\title{
Development and Evaluation of Localized Digital Learning Modules for Indigenous Peoples' Health Education in the Philippines
}

\author{
Julius Ceazar G. Tolentino, ${ }^{1, *}$, John Paul P. Miranda ${ }^{2}$, Vernon Grace M. Maniago ${ }^{2}$, Vanessa B. Sibug ${ }^{1}$ \\ ${ }^{1}$ Department of Physical Education, College of Education, Don Honorio Ventura State University, Philippines \\ ${ }^{2}$ Department of Information Technology, College of Computing Studies, Don Honorio Ventura State University, Philippines
}

Received September 15, 2020; Revised November 4, 2020; Accepted November 29, 2020

\section{Cite This Paper in the following Citation Styles}

(a): [1] Julius Ceazar G. Tolentino, John Paul P. Miranda, Vernon Grace M. Maniago, Vanessa B. Sibug, "Development and Evaluation of Localized Digital Learning Modules for Indigenous Peoples' Health Education in the Philippines," Universal Journal of Educational Research, Vol. 8, No. 12, pp. 6853 - 6862, 2020. DOI: 10.13189/ujer.2020.081251.

(b): Julius Ceazar G. Tolentino, John Paul P. Miranda, Vernon Grace M. Maniago, Vanessa B. Sibug (2020). Development and Evaluation of Localized Digital Learning Modules for Indigenous Peoples' Health Education in the Philippines. Universal Journal of Educational Research, 8(12), 6853 - 6862. DOI: 10.13189/ujer.2020.081251.

Copyright $(2020$ by authors, all rights reserved. Authors agree that this article remains permanently open access under the terms of the Creative Commons Attribution License 4.0 International License

\begin{abstract}
The fusion of indigenization and technology-integration in the teaching-learning process in the Philippines is both a trend and a challenge especially to indigenous peoples' education (IPEd). Hence, this study was sought to develop digital modules (DMs) in select topics in health education with an emphasis on hygiene among indigenous pupils in the Division of Mabalacat City, Pampanga, Philippines. Anchored on a descriptive action research paradigm, utilizing research and development design, IPEd teachers and culture bearers were purposely identified to aid in the development and validation phase. Moreover, the DMs were evaluated by pedagogy experts, basic education teachers in health education, and educational technology experts in terms of three factors such as content, instructional, and technical quality. Mean scores revealed that the DMs were found to be "very satisfactory". This indicated that the developed and evaluated materials were perceived to be acceptable for mainstream use given that the content and the elements were crafted out of localized concepts and placed together in a digital platform. This study was the initial phase of a mobile integrated learning system project to promote community engagement through science and technology (CEST) in the Philippines. It is recommended that the DMs be engineered in a mobile integrated system hardware to be extended as a learning material for the indigenous pupils.
\end{abstract}

Keywords Localized Learning Modules, Indigenous
People's Health Education, Computer-assisted Instruction, K To 12 Education

\section{Introduction}

One of the essential aims of 21 st-century learning is the promotion of technological skills as it adapts to the fast-changing and dynamic global arena, putting into emphasis the 4Cs: critical thinking and problem-solving; communication; collaboration; and creativity and innovation. In order to address such skills, emerging curricula should be anchored on empowering modern-day pedagogies along with the enhancement of innovation skills and ICT integration in education [14] [23] [25]. Also, cognizant to the United Nations' Sustainable Development Goals, particularly on Goal 4, which is to "ensure inclusive and equitable quality education and promote lifelong learning opportunities for all", it is imperative that educational institutions all over the world be given equal access and opportunities, specifically in the context of information and communication technology (ICT) in education. In fact, Kingsley [1] affirmed that third world countries for one, in order to be on a par with the global educational position, must be provided with substantial ICT programs, projects, and facilities. Relatively, it is 
envisioned that by 2030, quality education must be achieved through the provision of harnessed technology, including "mobile learning" as indicated in the Quingdao Declaration of 2015 [21].

In the Philippines, quality education has always been a priority and it is mandated by the constitution that education be given the highest budget priority. Educational programs, through legislations, were also institutionalized to give equitable access to quality education such as the Indigenous Peoples' (IP) Education, through the Indigenous Peoples' Rights Act of 1997 and with the advent of the implementation of Republic Act 10533 or the "Enhanced Basic Education Act of 2013" which firmly promotes a culture-responsive, culture-sensitive, integrative, contextualized, relevant and responsive curriculum since its initial take-off in 2013. Moreover, the Health Education curriculum aims to situate the learner to be able to "achieve, sustain and promote lifelong health and wellness". Also, the Grade 4-6 key stage standard aims that the learner will be able to "demonstrate an understanding of how changes as s/he grows and develops impact on healthy practices to help achieve and sustain the desired level of health." As such, one major consideration in implementing the curricula is to provide meaningful learning experiences, including the indigenous peoples to respond to their right "...to basic education that is responsive to their context, respects their identities, and promotes the value of their indigenous knowledge, skills, and other aspects of their cultural heritage" [7].

The use of ICT among IPs has been investigated in multiple contexts [9], [10], [11], [13], while the development, considerations, and integration of culturally-relevant teaching techniques and pedagogies for learners from diverse backgrounds in classroom settings were specifically explored in various studies as well [2], [4], [11], [18], [19], [20]. For one, Byrd [2] explored the effectiveness of culturally relevant teaching methods towards improved learning outcomes, increased engagement, and minimized achievement gaps among learners. Furthermore, Byrd [2] analyzed the learners' perspectives and concluded that academic outcomes are closely related to culturally relevant pedagogies [19]. The use of such pedagogies has proven to have a positive impact on learners [4], [11], [18], [20]. Moreover, the addition of existing knowledge from the community has manifested benefits for socially diverse learners [18].

In terms of sanitation and hygienic practices, low income and developing countries still lag in it [24] as it was reported that promoting proper sanitation and its cultivation as a habit among local communities is still a challenge among marginalized communities [25]. Moreover, the lack of proper information on hygiene and sanitation practices is still a threat among developing countries. Such scenarios often lead to disease outbreaks [24]. In contrast, the impact of improved sanitation practices in socio-economic development is relatively significant particularly among developing countries [27]. Additionally, Joshi and Amadi [26] highlighted the importance of hygienic education among children. Their involvement, including participation of the community, plays a vital role in ensuring that proper information on hygiene and sanitation practices is delivered among communities [24] [25]. Furthermore, ensuring that the right information is communicated to people is important towards improving sanitation practices [24]. It was reported that effective intervention such as promoting proper long-term behavioral change in hygiene practices (i.e., hand-washing) based on their social and cultural background is important to reduce the spread of diseases (e.g., typhoid \& cholera) [28] [29].

In the case of the Philippines, the Department of Education (DepEd) released Department Order 10, series of 2016 which is also known as the Comprehensive Water, Sanitation, Hygiene in School (WinS) program, which aims to amplify the efforts of schools to promote the proper way towards personal hygiene and sanitation practices. It is also intended to improve the safety and health of the school and its learners. The said program is focused on five (5) main parts: 1) ensuring the learners acquire the right information; 2) improving equitable access to hygiene and sanitation facilities; 3) educating learners using the right personal hygiene and sanitation practices; 4) implementing food sanitation and safeguarding educational institution from improper solid waste management threats (i.e., vector-borne diseases); and 5) involving stakeholders during its implementation for the sustainability of the program [6].

The authors, being faculty members in a state-funded higher education institution, wanted to contribute their share in uplifting the quality of instruction in basic education, particularly among indigenous peoples. Considering that along with the existence of state universities in the Philippines, the provision of solutions to the challenges of the community through its areas of strength and capacities is of primordial consideration. The researchers, both from the field of health and physical education and information technology, attempted to attain the goal of generating a platform where technology and indigenization be fused to enable IP pupils to be on a par with the mainstream educational technology.

Therefore, the researchers aimed to develop modules in health education for elementary pupils from indigenous peoples' education (IPEd) schools in the Division of the City of Mabalacat, Pampanga, Philippines. Specifically, the following questions were addressed: (1) What are the topics in health education that emerged from the needs analysis conducted in the locale? (2) How are these emerging topics developed into digital learning modules? (3) How do experts evaluate the modules in terms of the following factors: content quality, instructional quality, and technical quality? 


\section{Materials and Methods}

\subsection{Research Design}

This quantitative and descriptive study was anchored on an action research paradigm. Research and development ( $R$ $\& \mathrm{D})$ design was also used to design and develop digital modules in health education with an emphasis on personal hygiene among IPEd schools in Mabalacat City, Pampanga, Philippines. Educational R \& D is a research process that aimed to design, develop, and evaluate educational outputs, products, and the like [22].

\subsection{Participants}

Indigenous peoples' educators $(n=4)$ were consulted from four target basic education schools identified by the Division of Mabalacat City as institutions catering to indigenous peoples' education, specifically among Aeta pupils. Of the four participants, one is a culture-bearer. A culture-bearer is defined by the National Commission for Culture and the Arts of the Philippines as an "individual who is recognized to possess the skills and techniques in doing a particular traditional art or craft." In the context of the study, the culture-bearer may also carry the ability to speak and communicate using the innate language used by the Aetas' daily living, specifically in the Mabalacat area which is Aeta Mag-antsi. Through unstructured interviews and consultations, topics which are of concern and interest based on their needs were identified. The unstructured interviews were essential in deciphering emerging topics of prime consideration in the lives of the indigenous pupils. The interviews focused on the personal observation of the IP educators among their pupils on personal hygiene practices. Meanwhile, consultations were conducted by returning to the IP educators to verify the veracity of the finalized critical topics on personal hygiene which eventually became the subject matter of the digital contents.
In terms of the evaluation of the modules, seven (7) experts were purposely identified based on the following inclusion criteria: elementary education (pedagogy) experts $(n=2)$; health education teachers $(n=3)$, and educational technology experts $(n=2)$. The inclusion of a multidisciplinary team to evaluate the digital modules was considered to capture the essential inputs to enhance the modules. The elementary education (pedagogy) experts came from a College of Education and their teaching experiences range from 10-20 years in service both from the basic and higher education. Moreover, health education teachers composed of two (2) basic education teachers and one (1) IP educator teaching health education were considered. Lastly, since digital technology was considered in the instructional materials developed, educational technology experts were also considered. The two (2) experts have strong backgrounds in educational technology as evidenced by their practice and training in technology in teaching and learning.

\subsection{Procedures}

\subsubsection{Preparatory Phase}

In this stage, the planning and conceptualization phase took place. Since learning content should be needs-based, actual visitation to the community was conducted. All details that are naturally evident in the surroundings were taken into consideration. These include the type of animals and plants available, the structure of the inhabitants' houses, their school, among others. Each teacher from each school was also interviewed on what possible topics should be best prepared into a digital material. Based on the findings of the interview, these were categorically mapped in the curriculum guide of DepEd for Health Education to verify the intended grade level, content area, quarter, and specific topics. After the curriculum mapping, these were verified back to the IP educators to verify their veracity and confirmation. 
Table 1. Curriculum Map (adapted from Bilbao et al. [14])

\begin{tabular}{|c|c|c|c|c|c|}
\hline Timeline (Quarter) & Content Standard & $\begin{array}{c}\text { Topics } \\
\text { Identified }\end{array}$ & Resources Available & $\begin{array}{c}\text { Teaching- } \\
\text { Learning Methods }\end{array}$ & Assessment \\
\hline Grade 1, 2nd Quarter & $\begin{array}{c}\text { The learner } \\
\text { demonstrates } \\
\text { understanding of the } \\
\text { proper ways of taking } \\
\text { care of one's health }\end{array}$ & Hand washing & $\begin{array}{c}\text { DepEd Curriculum Guide } \\
\text { for Health Education } \\
\text { Digital Modules }\end{array}$ & $\begin{array}{c}\text { Demonstration } \\
\text { Method }\end{array}$ & $\begin{array}{c}\text { Reflection } \\
\text { Performance } \\
\text { task }\end{array}$ \\
\hline Grade 1,2nd Quarter & $\begin{array}{c}\text { The learner } \\
\text { demonstrates } \\
\text { understanding of the } \\
\text { proper ways of taking } \\
\text { care of one's health }\end{array}$ & Taking a bath & $\begin{array}{c}\text { DepEd Curriculum Guide } \\
\text { for Health Education } \\
\text { Digital Modules }\end{array}$ & $\begin{array}{c}\text { Lecturettes and } \\
\text { game-based } \\
\text { strategies }\end{array}$ & $\begin{array}{c}\text { Reflection } \\
\text { Self-Checklist }\end{array}$ \\
\hline Grade 1,3rd Quarter & $\begin{array}{c}\text { The learner } \\
\text { demonstrates } \\
\text { understanding of the } \\
\text { proper ways of taking } \\
\text { care of one's health }\end{array}$ & Tooth brushing & $\begin{array}{c}\text { DepEd Curriculum Guide } \\
\text { for Health Education } \\
\text { Digital Modules }\end{array}$ & $\begin{array}{c}\text { Demonstration } \\
\text { Method }\end{array}$ & $\begin{array}{c}\text { Reflection } \\
\text { Self-Checklist } \\
\text { Performance } \\
\text { task }\end{array}$ \\
\hline Grade 5, 2nd Quarter & $\begin{array}{c}\text { The learner describes } \\
\text { physical changes in } \\
\text { puberty }\end{array}$ & Menstruation & $\begin{array}{c}\text { DepEd Curriculum Guide } \\
\text { for Health Education } \\
\text { Digital Modules }\end{array}$ & $\begin{array}{c}\text { Lecturettes and } \\
\text { game-based } \\
\text { strategies }\end{array}$ & $\begin{array}{c}\text { Reflection } \\
\text { Self-Checklist }\end{array}$ \\
\hline
\end{tabular}

\subsubsection{Development Phase}

Liu et al. [3] highlighted the demand of engaging multimedia content like animated instructional videos in the modern age of education. This is significant to perform the functions of presenting complex information and capturing student interest in the learning process. The animation of the media elements such as the background scenes and characters were created to effectively convey the learning content to the intended users. Storyboards were used to make the sequence of the scenes of the digital modules. A storyboard is essentially a rough draft of animation to see what the output might look like for the first time. The media elements were imported and arranged using the Adobe Animate CC, a multimedia authoring and animation program. For the motion of the animations to appear smooth, the researchers used 24 frames per second (fps). Keyframes were set using frame-by-frame and inbetweening animation processes to apply motion and timings in the scenes. After the setting up of keyframes, a skeletal model was formed by animating specific parts of the characters and applied cleanup to the $2 \mathrm{D}$ vectors to improve the imagery details. Debug testing in every animation command was performed to check the frames in motion. The application of voice, music, and special effects took place after the composition and editing of the scenes. Finally, a 2D movie was rendered to bring animation to life.

\subsubsection{Evaluation Phase}

In this phase, the adoption of an instrument in the evaluation of non-print (digital materials) provided by the Department of Education (DepEd) was utilized and is open to access on the Internet. The tool was essential in describing the validity of the digital modules in terms of content quality, instructional quality, and technical quality.

\subsection{Instrument}

In evaluating the digital modules, the "Evaluation Rating Sheet for Non-Print Materials" from the "Guidelines and Processes for Learning Resources Management and Development System (LRMDS) Assessment and Evaluation V1.0" [5] was used. This instrument was found to be the most suitable since the intended users will be basic education pupils, hence it would be essential to consider the prescribed criteria provided by DepEd. Three (3) factors were considered in the tool, namely: (a) content quality (10 items); (b) instructional quality (10 items); and (c) technical quality (13 items). These were rated using a four-point Likert scale with 4 as "very satisfactory" to 1 as "not satisfactory".

\subsection{Data-Gathering Procedures}

Permission to conduct the study was sought through the aid of the Research and Development Services Office. Then, the superintendent of the Division of Mabalacat City was initially consulted and was asked for approval to conduct the study since the basic education schools are within the division's jurisdiction. The target schools were identified as educational institutions that cater to indigenous pupils, particularly the Aetas from the upland barangays of Mabalacat City, Pampanga. Referral to the school principals/headteachers aided the facilitation of 
interviews among their health education teachers.

After the conduct of the first and second phases of the procedures, the evaluation of the modules took place. All digital modules were stored via Google Drive and a link was generated to share the materials with the expert-evaluators. Another link was also provided for them to access the evaluation tool using Google Forms.

During the conduct of the study, the identity of the respondents was kept anonymous. The data generated from their evaluation were also treated with full confidentiality. Series of consultations were also conducted among culture-bearers to ensure that all aspects (visual elements and language used) included in the module were reflective of their cultural identity.

\subsection{Data Analysis}

In order to interpret the results of the experts' assessment, descriptive statistics such as mean $(\bar{X})$ was used. Mean scores were interpreted using the following ranges and their corresponding verbal description (VD).

\begin{tabular}{|c|c|}
\hline Statistical Ranges & Verbal Description \\
\hline $3.21-4.0$ & Very Satisfactory (VS) \\
\hline $2.61-3.20$ & Satisfactory (S) \\
\hline $1.81-2.60$ & Poor (P) \\
\hline $1.0-1.80$ & Not Satisfactory (NS) \\
\hline
\end{tabular}

\section{Results and Discussion}

\subsection{Emerging Topics from the Needs Assessment Analysis}

Several visits were conducted to the actual sites where the elementary schools were situated. Interviews with health education teachers as well as the school vicinity/site observations were documented to determine the extent of the need to develop modules for health education.
A comprehensive review of the Department of Education's recommended curriculum for health education was conducted. This phase attempted to align the emerging needs with that of the existing curriculum guide provided by DepEd. By doing so, this would facilitate the identification of intended learners (grade level), health content area, quarter, and specific topics where the modules will be benchmarked. Then, a semi-detailed curriculum mapping was conducted. Bilbao et al. [14] defined curriculum mapping as the next phase after a certain curriculum has been designed and it is also a process conducted prior to the actual implementation of the content/subject matter. Although curriculum mapping may be associated with broad fields of study (e.g. an undergraduate or graduate degree program, basic education curriculum, etc.), this study utilized the same process but in a semi-detailed design in structuring and aligning the emerging topics from the locale since there is a deemed necessity as articulated by the IP educators themselves. Table 2 shows a semi-detailed curriculum map from the emerging topics vis-à-vis the curriculum guide provided by DepEd for Health Education. The semi-detailed curriculum map shall serve as a basis in the implementation of the topics. It could be surmised in Table 2 that the identified topics were mostly intended for Grade 1 pupils and targeted the Health Content Area of "Personal Health" for 2nd and 3rd quarters. This implies that the modules may be intended to address these topics for grade 1 pupils as this is the stage where they are expected to have an explicit awareness of taking good care of their own health to develop health literacy skills and later on, manifest a good sense of well-being [8]. Surprisingly, another emerging topic of concern was on menstruation, which is technically intended for female pupils and was introduced to them in their fifth grade, second quarter. The emphasis of the topic conforms to the health content area of "growth and development". As this stage approached the onset of puberty, this was identified as a subject matter that seems very challenging to health educators primarily in the indigenous schools.

Table 2. A semi-detailed curriculum map aligning the emerging topics to the DepEd's Health Education curriculum guide

\begin{tabular}{|c|c|c|c|c|}
\hline \multirow{2}{*}{$\begin{array}{l}\text { Emerging } \\
\text { Topics }\end{array}$} & \multicolumn{4}{|c|}{ Alignment in the $\mathrm{K}$ to 12 Curriculum Guide for Health Education of the Department of Education } \\
\hline & Grade Level & Health Content Area & Quarter & Specific Topic/s \\
\hline Hand washing & 1 & Personal Health & 2nd Quarter & $\begin{array}{c}\text { Health Habits and Hygiene } \\
\text { Hand washing } \\
\text { Wiping hands and face with a clean handkerchief }\end{array}$ \\
\hline Taking a bath & 1 & Personal Health & 2nd Quarter & $\begin{array}{c}\text { Health Habits and Hygiene } \\
\text { Wearing clean clothes day and night }\end{array}$ \\
\hline Tooth brushing & 1 & Personal Health & 3rd Quarter & $\begin{array}{l}\text { Health Habits and Hygiene } \\
\text { Care of the eyes, ears, nose, mouth/ teeth, hair, skin, etc. } \\
\text { Tooth brushing and flossing }\end{array}$ \\
\hline Menstruation & 5 & $\begin{array}{l}\text { Growth and } \\
\text { Development }\end{array}$ & 2nd Quarter & $\begin{array}{l}\text { Physical changes during puberty } \\
\text { Myths and misconceptions related to physical changes during puberty } \\
\text { Management of puberty-related physical problems } \\
\text { Personal health care during puberty }\end{array}$ \\
\hline
\end{tabular}




\subsection{Development of the Modules}

In the development process, the initial designs were first drafted then validated by the IPEd teachers. Upon approval, the latest version of Adobe Animate (formerly known as Adobe Flash) was used to develop the content of the modules (e.g., hand washing (see Figure 3), taking a bath and wearing of slippers (see Figures $4 \& 5$ ), tooth brushing (see Figure 6), and menstruation (see Figure 7) including the creation of all 2D vector images (e.g., characters, clouds, \& trees). Then, Adobe Photoshop CC was used to enhance the colors and depths of each element. It is also important to take note that all elements (e.g., background scene \& characters) found in the modules are tailored specifically for the indigenous people (see Figures $1 \& 2$ ). Varying images, videos, interviews, and observations from the locale were considered in developing these elements for the module to be more attractive, catchy, and reflective of their daily life.

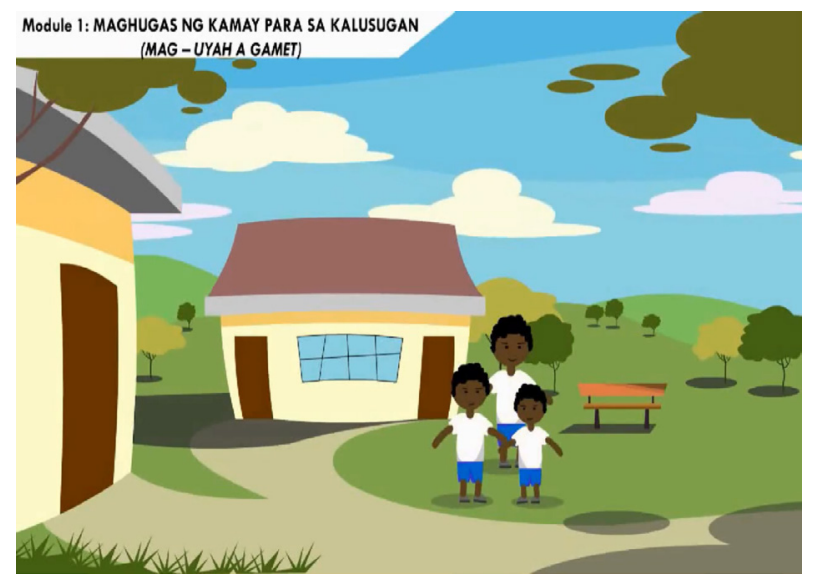

Figure 1. Screen-captured image of a scene in the digital storytelling

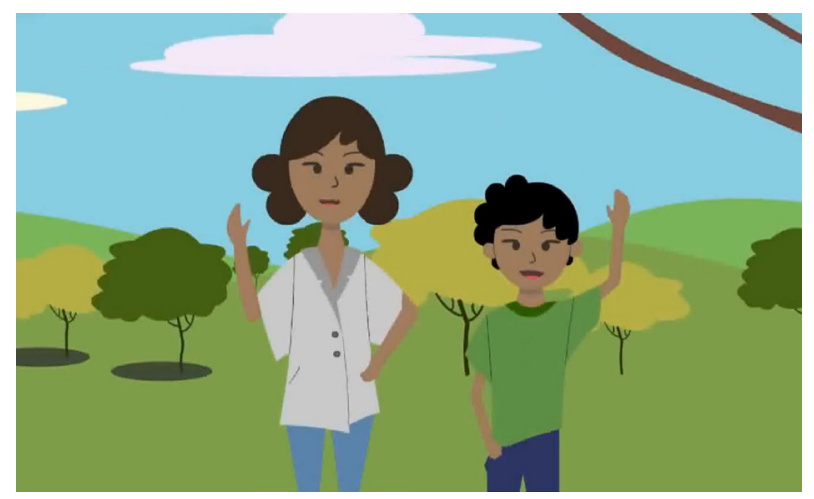

Figure 2. Main personas (Kaka Cila [left] and Jun [right]) in the localized digital module

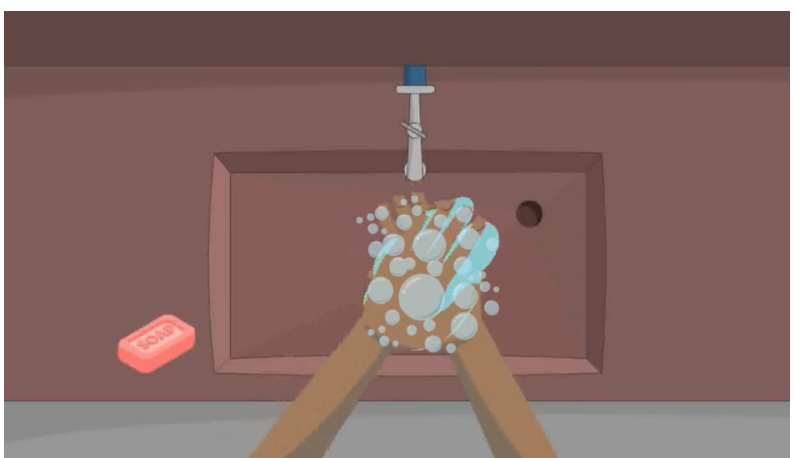

Figure 3. Clip from the demonstration of proper handwashing

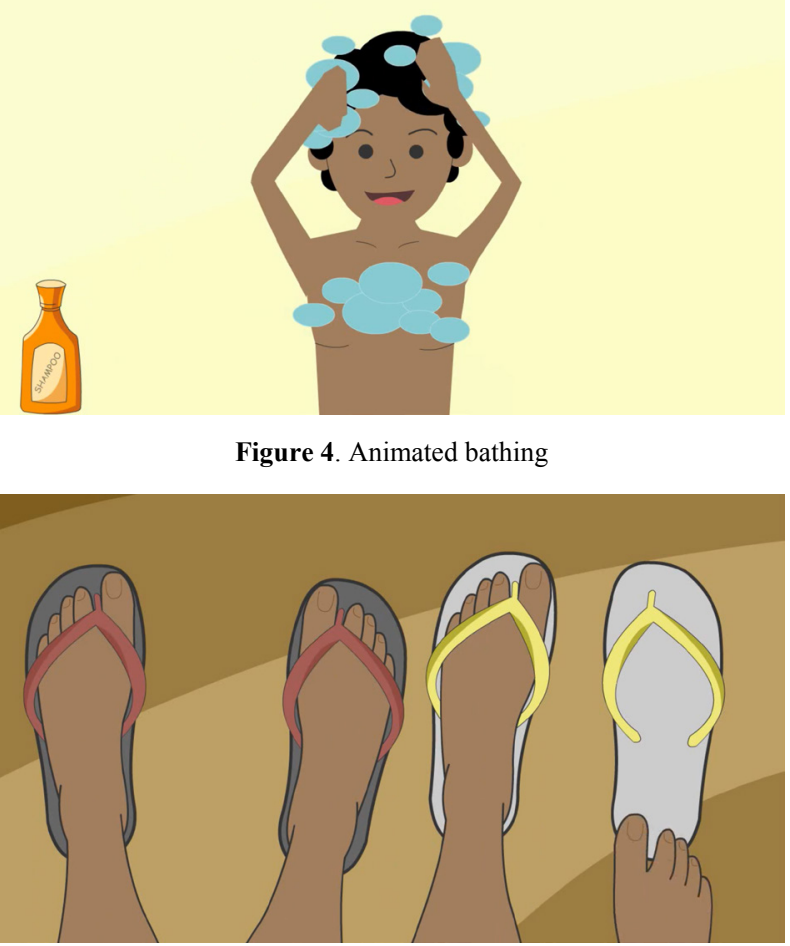

Figure 5. Wearing of slippers

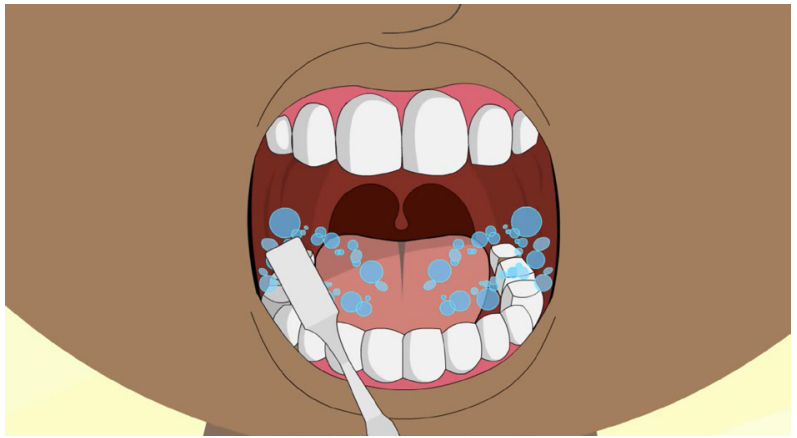

Figure 6. Animated tooth brushing scene 


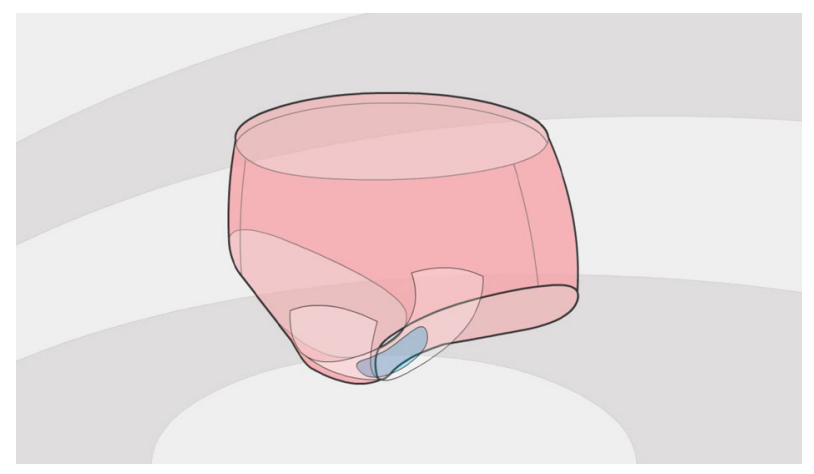

Figure 7. Clip from proper menstrual hygiene practices

Several considerations were included towards the creation of content for the digital modules and this study recognized the need for more culturally-aware content to better suit the needs of the intended users, which in this case, are the IPs of Mabalacat, Pampanga. One consideration is that most IPs tend to be visual learners [9] and mostly they use ICT resources for educational purposes [19]. Moreover, the intended users' cultural orientation and their contexts were considered in designing the scenes and personas (see Figure 2) to be used in the learning modules. Such design considerations are very important due to their impact on the learning process [15]. For example, Yao [16] developed a culture-based module for mathematics in consideration of the learning context of IPs while Dasman and Yasin [17] posited that the creation of such modules should suit the needs of the community and prioritize the needs of learners. More so, the creation and incorporation of culturally relevant learning materials particularly using digital storytelling are highly sought towards authentic and equitable learning [12], [18]. Applications such as Adobe Photoshop CC and Adobe Animate $\mathrm{CC}$ were used for the localized graphics (i.e., fruits found within their community) and animations to be incorporated in each scene.

\subsection{Evaluation of the Digital Modules}

\subsubsection{Content Quality}

Table 3 presents the experts' evaluation in terms of the first factor which is content quality. It could be noted that all items that fall under this factor were given a verbal description (VD) of "very satisfactory". Given a grand mean of 3.90, overall, the quality of the contents of the digital modules was perceived to be "very satisfactory". Remarkably, a concurred mean of 4.00 was seen on several indicators such as: "Content is consistent with topics/skills found in the DepEd. Learning Competencies for the subject and grade/year level it was"; "Content is accurate"; "Content is free from cultural, gender, racial, or ethnic bias"; "Content is relevant to real-life situations"; and
"Content promotes positive values that support formative growth". This indicates that the developed contents of the digital modules were found to be adherent to the standards of the Department of Education of providing quality learning materials that are gender-oriented and culturally sensitive. This could be justified by the provision of characters in the digital stories where Aeta mag-antsi children were included to make it more indigenized and localized. Moreover, the scenes included were also adopted from the actual locality during the immersion to the site and such recommendations of inclusions were also emphasized by the IP educators.

Table 3. Evaluation of the modules in terms of content quality

\begin{tabular}{|l|c|c|}
\hline \multicolumn{1}{|c|}{ Factor A: Content Quality } & $\bar{X}$ & VD \\
\hline $\begin{array}{l}\text { 1. Content is consistent with topics/skills found in the } \\
\text { DepEd. Learning Competencies for the subject and } \\
\text { grade/year level it was. }\end{array}$ & 4.00 & VS \\
\hline $\begin{array}{l}\text { 2. Concepts developed contribute to enrichment, } \\
\text { reinforcement, or mastery of the identified learning } \\
\text { objectives. }\end{array}$ & 3.86 & VS \\
\hline \begin{tabular}{l} 
3. Content is accurate. \\
\hline 4. Content is up-to-date.
\end{tabular} & 4.00 & VS \\
\hline \begin{tabular}{l} 
5. Content is logically developed and organized. \\
\hline $\begin{array}{l}\text { 6. Content is free from cultural, gender, racial, or } \\
\text { ethnic bias. }\end{array}$
\end{tabular} & 3.7100 & VS \\
\hline 7. Content stimulates and promotes critical thinking. & 3.71 & VS \\
\hline 8. Content is relevant to real-life situations. & 4.00 & VS \\
\hline $\begin{array}{l}\text { 9. Language (including vocabulary) is appropriate to } \\
\text { the target user level. }\end{array}$ & 3.86 & VS \\
\hline $\begin{array}{l}\text { 10. Content promotes positive values that support } \\
\text { formative growth. }\end{array}$ & 4.00 & VS \\
\hline & 3.90 & VS \\
\hline
\end{tabular}

\subsubsection{Instructional Quality}

Reflected in Table 4 is the evaluation of the experts in terms of the instructional quality of the digital modules. Similarly, all items under instructional quality as a factor were all described to be "very satisfactory" due to mean ratings ranging from 3.71 to 4.00 and a grand mean of 3.81 . The lone item that obtained a concurred evaluation from the experts is the item "Purpose of the material is well defined". This is an indication that the materials truly embody the essence of the health education concepts provided in the digital modules. Moreover, the modules were perceived to have coherent instruction from the identification of objectives to the evaluation of learning. Indicative of the results, the expert-respondents were very satisfied with the quality of instruction provided in the proper sequencing and selection of elements to stimulate the learners' senses, promote engagement, and activate their prior existing knowledge in relation to the content. 
Table 4. Evaluation of the modules in terms of instructional quality

\begin{tabular}{|l|c|c|}
\hline \multicolumn{1}{|c|}{ Factor B: Instructional Quality } & $\bar{X}$ & VD \\
\hline 1. Purpose of the material is well defined. & 4.00 & VS \\
\hline 2. Material achieves its defined purpose. & 3.86 & VS \\
\hline 3. Learning objectives are clearly stated and measurable. & 3.71 & VS \\
\hline 4. Level of difficulty is appropriate for the intended target user. & 3.86 & VS \\
\hline 5. Graphics / colors / sounds are used for appropriate instructional reasons. & 3.86 & VS \\
\hline 6. Material is enjoyable, stimulating, challenging, and engaging & 3.86 & VS \\
\hline 7. Material effectively stimulates creativity of target users. & 3.86 & VS \\
\hline 8. Feedback on target user's responses is effectively employed & 3.71 & VS \\
\hline 9. Target user can control the rate and sequence of presentation and review. & 3.71 & VS \\
\hline 10. Instruction is integrated with the target user's previous experience. & 3.71 & VS \\
\hline Grand Mean & 3.81 & VS \\
\hline
\end{tabular}

\subsubsection{Technical Quality}

Table 5. Evaluation of the modules in terms of technical quality

\begin{tabular}{|l|c|c|}
\hline \multicolumn{1}{|c|}{ Factor C: Technical Quality } & $\bar{X}$ & VD \\
\hline 1. Audio enhances understanding of the concept & 3.75 & VS \\
\hline $\begin{array}{l}\text { 2. Speech and narration (correct pacing, intonation, and pronunciation) is clear and can be easily } \\
\text { understood. }\end{array}$ & 3.57 & VS \\
\hline 3. There is complete synchronization of audio with the visuals, if any. & 3.43 & $S$ \\
\hline 4. Music and sound effects are appropriate and effective for instructional purposes. & 3.71 & VS \\
\hline 5. Screen displays (text) are uncluttered, easy to read, and aesthetically pleasing. & 3.71 & VS \\
\hline 6. Visual presentations (non-text) are clear and easy to interpret. & 3.86 & VS \\
\hline 7. Visuals sustain interest and do not distract the user's attention. & 3.86 & VS \\
\hline 8. Visuals provide accurate representation of the concept discussed. & 3.71 & VS \\
\hline 9. The user support materials (if any) are effective & 3.57 & VS \\
\hline 10. The design allows the target user to navigate freely through the material. & 3.86 & VS \\
\hline 11. The material can easily and independently be used. & 3.71 & VS \\
\hline 12. The material will run using minimum system requirements. & 3.00 & VS \\
\hline 13. The program is free from technical problems. & 3.65 & $S$ \\
\hline \multicolumn{1}{|c|}{ Grand Mean } & VS \\
\hline
\end{tabular}

Indicated in Table 5 are the results of the evaluation of the expert-respondents in terms of the technical quality of the modules. Most of the items were perceived to be "very satisfactory" with mean scores ranging from 3.57-4.00. This signifies that the audio-visual properties of the digital modules were thought to be very satisfying. The visual elements such as the personas and the texts were appreciated by the expert-respondents due to the creative and colorful elements in it that are recommended for elementary pupils. However, there were two (2) items that reflected a "satisfactory" remark by the expert-respondents: "There is complete synchronization of audio with the visuals if any" and "The program is free from technical problems". Even though these two items were still perceived to be "satisfactory", these were attributed to some minor synchronization issues with personas and that of the audio in the story-telling scenes. Nonetheless, these were eventually addressed in the improvement phase of the process. Overall, when considering the technicalities of the modules as digital instructional materials, they were evaluated to be "very satisfactory" by the expert-respondents as evidenced by a grand mean of 3.65.

\section{Conclusions and Recommendations}

With respect to the results of the study, it was concluded that digital modules can be developed by putting into premium the conduct of a needs assessment analysis as a requisite to content development in the curriculum process 
specifically when technology integration and indigenization are concerned. Through this, more responsive content would be developed along with the contextualization of instruction. Also, to make it more compliant with the requirements of the Department of Education through their written curriculum, content mapping was found to be essential after identifying the topics that emerged from the needs analysis. It was given emphasis that digital technology may be integrated in the teaching-learning process to keep the indigenous learners on a par with the mainstream and global education arena.

Grounded on the premise of development and evaluation of the proposed materials after adopting an $\mathrm{R} \& \mathrm{D}$ design, it would be recommended that the digital modules be engineered in a mobile integrated learning system hardware to make it operational. Moreover, after the completion of the hardware, it is also recommended that the entire instructional material (IM) be implemented to the target schools to verify the acceptability of the teachers and the pupils. A comprehensive training on the operationalization of the material among the IP educators is also recommended to enable them to facilitate the use of the IM and eventually include more content from different subject areas. With these, collaborative action research may also be explored as an area of future research undertaking to capture the acceptability of the IM and be a basis for enhancement of the software and hardware components of the IM.

\section{Limitations of the Study}

Several research limitations were identified towards the completion of the study. For instance, the integration of the digital modules into a hardware component was not yet considered due to a limited number of topics identified since these are just part and parcel of a more detailed component of the Health Education curriculum. This could be facilitated after the development of more modules that covers the entirety of the contents. Another limitation identified was the use of descriptive statistics in the evaluation of the modules. The rich quality of feedback was not explicitly explored through a qualitative inquiry to supplement the quantitative results. The recommendations for the improvement of the contents of the modules were gathered verbally but were not included in the data analysis. However, the experts' suggestions were included in the enhancement of the digital modules. To enable the operationalization and completion of the instructional material, these limitations posted in the initial phase may be explored in the second phase of the mobile integrated learning system project facilitated by the authors along with the experts in electronics engineering. Eventually, it was acknowledged that composing a multidisciplinary team of researchers may be essential in addressing the challenges in the education sector in providing equity and access through technology integration.

\section{Acknowledgments}

The authors would like to express their profound and sincerest gratitude to the Don Honorio Ventura State University for funding this study. Thanks are also due to the Schools Division of Mabalacat City and to the respondents of this study.

\section{REFERENCES}

[1] Kingsley, A., "Information communication technology (ICT) in the educational system of the third world countries as a pivotal to meet global best practice in teaching and development," American Journal of Computer Science and Information Technology, vol. 5, no. 2, pp 1-5, 2017. DOI: 10.21767/2349-3917.100010.

[2] Byrd, C., "Does Culturally Relevant Teaching Work? An Examination from Student Perspectives," SAGE Open, pp. 1-10, 2016. DOI: 10.1177/2158244016660744.

[3] Liu C. \& Elms, P., "Animating student engagement: The impacts of cartoon instructional videos on learning experience," Research in Learning Technology, vol. 27, 2019. DOI: $10.25304 /$ rlt.v27.2124.

[4] Martell, C., "Race and Histories: Examining Culturally Relevant Teaching in the U.S. History Classroom," Theory \& Research in Social Education, vol. 41, no. 1, pp. 65-88, 2013. DOI: $10.1080 / 00933104.2013 .755745$.

[5] Department of Education, "Guidelines and processes for LRMDS assessment and evaluation. (Version: Final Draft 1.0),"

https://lrmds.deped.gov.ph/docs/LRMDSGuidelines.pdf, (accessed August 13, 2020).

[6] Department of Education, "DepEd Order 10, s. 2016: policy and guidelines for the comprehensive water, sanitation and hygiene in schools (WINS) program, 2016.

[7] Department of Education, "DepEd Order No. 22 s. 2016 Implementing guidelines on the allocation and utilization of the indigenous peoples' education (IPEd) program support fund for fiscal year (FY) 2016"

[8] Department of Education, K to 12 Health Curriculum Guide, http://depedbohol.org/v2/wp-content/uploads/2016/03/Healt h-CG_with-tagged-math-equipment.pdf, (accessed September 08, 2020)

[9] Stefos, E., Castellano, J. M., Marchán, A. B., \& Biloon, J. R. S., "The use of new technologies in basic education: an approach to profile of indigenous Ecuadorians," International Journal of Education Methodology, vol. 3, no. 1, pp. 31-40, 2017. DOI: /10.12973/ijem.3.1.31.

[10] Tuazon, I. M., "Implementation of DepEd Computerization Program (DCP) for the Indigenous People," Asian Journal of Educational Research, vol. 7, no. 1, pp. 1-14, 2019.

[11] Luaran J. E., Nadzri, F. A., Rom, K. B. M., \& Jain, J., “The Importance of Information and Communication Technology in English Learning: Indigenous Students' Perspectives," Malaysian Journal of Distance Education, vol. 18, no. 1, pp. 
87-101, 2016. DOI: 10.21315/mjde2016.18.1.6.

[12] Loewen, J., Suhonen, J., \& Chen, N. S., "I-SLATE: designing a culturally relevant framework for authentic learning," Smart Learning Environments, vol. 4, no. 1, p. 9, 2017.

[13] Osman, M. J., Idris, N. H., \& Idris, N. H., "Paper versus Screen: Assessment of Basic Literacy Skill of Indigenous People," Advanced Science Letters, vol. 23, no. 9, pp. 8752-5757, 2017. https://doi.org/10.1166/asl.2017.9964.

[14] Bilbao, P. B., Dayagbil, F. T., \& Corpuz, B. B., "Curriculum development for teachers," Quezon City, Philippines: Lorimar Publishing, Inc., 2015.

[15] Jarvis, P., Holford, J., \& Griffin, C., "The theory and practice of learning," London: Kogan Page, Limited, 1998. DOI: .10.4324/9780203465653

[16] Yao, R., "Creating learning environments for indigenous students through cultured-based math modules," Universal Journal of Educational Research, vol. 4, no. 8, pp. 1809-1814, 2016. DOI: 10.13189/ujer.2016.040810.

[17] Dasman, S. M. \& Yasin, R. M., "Design of environmental education module towards the needs of aboriginal community learning" In M. Puteh, N. Z. A. Hamid, \& N. H. Adenan (Eds.), International Conference on Education, Mathematics and Science 2016 (ICEMS2016) in Conjunction with International Postgraduate Conference on Science and Mathematics 2016 (IPCSM2016) (80002). AIP Publishing. DOI: 10.1063/1.4983914.

[18] Piazza S., Rao, S., \& Protacio, M. S., "Converging Recommendations for Culturally Responsive Literacy Practices: Students with Learning Disabilities, English Language Learners, and Socioculturally Diverse Learners," International Journal of Multicultural Education, vol. 17, no. 3, pp. 1-20, 2015.

[19] Watson, S., "New Digital Technologies: Educational Opportunities for Australian Indigenous Learners," The Australian Journal of Indigenous Education, vol. 42, pp. 58-67, 2013. DOI: 10.1017/jie.2013.8.

[20] Epstein, T., Mayorga, E., \& Nelson, J., "Teaching about Race in an Urban History Class: The Effects of Culturally
Responsive Teaching," The Journal of Social Studies Research, vol. 35, no. 1, p. 2, 2011.

[21] UNESCO, “Qingdao Declaration, 2015: Sixteen Digital Opportunities, Lead Education Transformation," 2015 https://unesdoc.unesco.org/ark:/48223/pf0000233352 (accessed September 01, 2020).

[22] Borg, W. R. \& Gall, M. D., "Educational Research: An Introduction," New York: David McKay Company. Inc., 1971.

[23] Nithyanantham, V. \& Shareef, S. "Integration of ICT for Transforming Education among the Non-Science Stream Pedagogical Learners," Universal Journal of Educational Research, vol. 7, no. 8, pp. 1690-1697, 2019. DOI: 10.13189/ujer.2019.070807

[24] Kumwenda, S. "Challenges to Hygiene Improvement in Developing Countries," The Relevance of Hygiene to Health in Developing Countries, IntechOpen, 2019. DOI: 10.5772/intechopen.80355

[25] Singavarapu, P. \& Murray, E. "Report on Impact of Inadequate Sanitation on the Marginalised," 2013. DOI: $10.13140 / 2.1 .4310 .3529$

[26] Joshi, A. \& Amadi, C. "Impact of Water, Sanitation, and Hygiene Interventions on Improving Health Outcomes among School Children," Journal of Environmental and Public Health, vol. 2013, 2013. DOI: 10.1155/2013/984626

[27] Mara, D., Lane, J., Scott, B., \& Trouba, D. "Sanitation and Health," PLoS Med, vol. 7, no. 11, 2010. DOI: 10.1371/journal.pmed.1000363

[28] Centers for Disease Control and Prevention, "Overview of Hygiene in Lower Income Countries," 2016. Retrieved from https://www.cdc.gov/healthywater/hygiene/ldc/index.html

[29] De Buck, E., Van Remoortel, H., Hannes, K., Govender, T., Naidoo, S., Avau, B., Vande veegaete, A., Musekiwa, A., Lutje, V., Cargo, M., Mosler, H., Vandekerckhove, P., \& Young T. "Approaches to promote handwashing and sanitation behaviour change in low- and middle-income countries: a mixed method systematic review," Campbell Systematic Reviews, vol. 13, no. 1, pp. 1-447, 2017. DOI: 10.4073/csr.2017.7 